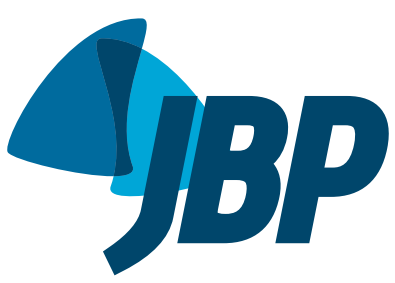

1. Departamento de Ciências Médicas, Universidade Nove de Julho, São Paulo (SP) Brasil.

2. Programa de Pós-Graduação em Gerenciamento Ambiental e Sustentabilidade, Universidade Nove de Julho, São Paulo (SP) Brasil.

Submitted: 3 November 2015. Accepted: 18 November 2016

Study carried out in the Departamento de Ciências Médicas, Universidade Nove de Julho, São Paulo (SP) Brasil.

\title{
Trends in asthma mortality in the 0 - to 4-year and 5- to 34-year age groups in Brazil
}

\author{
Gustavo Silveira Graudenz ${ }^{1,2}$, Dominique Piacenti Carneiro1, \\ Rodolfo de Paula Vieira'
}

\begin{abstract}
Objective: To provide an update on trends in asthma mortality in Brazil for two age groups: 0-4 years and 5-34 years. Methods: Data on mortality from asthma, as defined in the International Classification of Diseases, were obtained for the 1980-2014 period from the Mortality Database maintained by the Information Technology Department of the Brazilian Unified Health Care System. To analyze time trends in standardized asthma mortality rates, we conducted an ecological time-series study, using regression models for the 0- to 4-year and 5- to 34-year age groups. Results: There was a linear trend toward a decrease in asthma mortality in both age groups, whereas there was a third-order polynomial fit in the general population. Conclusions: Although asthma mortality showed a consistent, linear decrease in individuals $\leq 34$ years of age, the rate of decline was greater in the 0- to 4-year age group. The 5- to 34-year group also showed a linear decline in mortality, and the rate of that decline increased after the year 2004, when treatment with inhaled corticosteroids became more widely available. The linear decrease in asthma mortality found in both age groups contrasts with the nonlinear trend observed in the general population of Brazil. The introduction of inhaled corticosteroid use through public policies to control asthma coincided with a significant decrease in asthma mortality rates in both subsets of individuals over 5 years of age. The causes of this decline in asthma-related mortality in younger age groups continue to constitute a matter of debate.
\end{abstract}

Keywords: Asthma/epidemiology; Asthma/mortality; Asthma/drug therapy.

\section{INTRODUCTION}

Asthma is a chronic inflammatory disease characterized by lower airway hyperresponsiveness and variable airflow limitation that are reversible either spontaneously or with treatment. The typical clinical features of asthma include recurrent episodes of wheezing, breathlessness, chest tightness, and coughing, particularly at night or in the early morning. ${ }^{(1)}$

According to the Brazilian Thoracic Association Guidelines for Asthma Management, ${ }^{(2)}$ there were 160,000 hospital admissions due to asthma exacerbations in 2011. The guidelines also state that asthma is the fourth leading cause of hospital admissions via the Brazilian Unified Health Care System as a whole, as well as being the third leading cause of hospital admissions among children and young adults. ${ }^{(2)}$

Although asthma-related deaths are relatively rare, they are considered to be of great importance because they are, in most cases, preventable through early diagnosis and appropriate treatment. According to the Global Initiative for Asthma, ${ }^{(1)}$ appropriate asthma treatment can retard lung inflammation and the subsequent tissue damage, thereby decreasing the frequency and intensity of asthma attacks. ${ }^{(1)}$

Increases in asthma morbidity and mortality have frequently been reported in most industrialized countries and in Brazil, primarily during the 1980 s and 1990 s..$^{(3-6)}$ The Asthma Insights and Reality in Latin America survey showed that the asthma morbidity rate is high throughout Latin America. ${ }^{(7)}$ The survey also showed that the vast majority of patients had not received an appropriate diagnosis, were not given appropriate therapy, were not adequately monitored, were failing to achieve the goals for asthma management set forth in international asthma guidelines, and were at risk for severe asthma attacks. ${ }^{(7)}$

Although the causes of the reported increase in the asthma burden are still largely unknown, the most relevant aspects are environmental, genetic, and behavioral factors, either alone or in combination. ${ }^{(8-10)}$ Recent studies have demonstrated that other factors could influence asthma mortality, such factors including the widespread use of anti-inflammatory asthma drugs, influenza vaccination campaigns, and broader social inclusion in the health care system, together with other initiatives, all of which could rapidly change the trends in asthma mortality. In a recent meta-analysis of asthma-related deaths, Wijesinghe et al. ${ }^{(11)}$ stressed the need to update the data and maintain surveillance on international asthma mortality trends, especially for the 5- to 34-year age group, because death certificate information (regarding the cause of death) is considered more accurate in that group. ${ }^{(11)}$ Despite the increased difficulty in making an accurate diagnosis in

Correspondence to:

Gustavo Graudenz. Departamento de Ciências Médicas, Universidade Nove de Julho, Rua Vergueiro, 44, Liberdade, CEP- 01503-001, São Paulo, SP, Brasil.

Tel.: 5511 3385-9124.E-mail: ggraudenz@gmail.com or graudenz@uninove.com.br

Financial support: This study received financial support from the Nove de Julho University Fundação de Incentivo à Pesquisa(FUNPESQ, Foundation for the Promotion of Research). 
children under 5 years of age, asthma-related deaths among such children have been included in analyses because of the reported increase in the prevalence of asthma and the historical importance of this age group to the overall rates of asthma morbidity and mortality. ${ }^{(12,13)}$ Therefore, the aim of this study was to provide an update on asthma mortality trends in Brazil for the 0- to 4-year and 5- to 34-year age groups between 1980 and 2014.

\section{METHODS}

\section{Study design}

This was an ecological time-series study that analyzed the trends in mortality from asthma. Crude and age-adjusted asthma mortality rates were calculated.

\section{Data collection}

Death certificates were obtained from the Mortality Database maintained by the Information Technology Department of the Brazilian Unified Health Care System (http://www.datasus.gov.br), filtered for asthma listed as the underlying cause of death in the 1980-2014 period. This database is composed of death certificates, organized on the basis of the codes established in the International Classification of Diseases, 9th and 10th revisions (ICD-9 and ICD-10, respectively). To obtain the total number of deaths attributed to asthma, we used the ICD-9 code 493 (asthma) for the 1980-1995 period, whereas we used the ICD-10 codes 345 (asthma) and J46 (status asthmaticus; i.e., acute severe asthma) for the 1996-2014 period. Initially, we calculated asthma mortality rates for the general population, after which we calculated those rates for two specific age groups: 0-4 years and 5-34 years.

\section{Asthma mortality rates}

Asthma mortality rates for the 1980-2014 period were calculated from annual demographic data and population estimates obtained from the Brazilian Institute of Geography and Statistics. We calculated the crude asthma mortality rates (per 100,000 population) and the age-adjusted asthma mortality rates.

\section{Statistical analysis}

In the modeling process, the dependent variable $(Y)$ was the polynomial coefficient for the asthma mortality rate and the independent variable $(X)$ was the calendar year. The coefficient of determination $\left(R^{2}\right)$ was used as a measure of the accuracy of the models. The models were tested for linear fitness $(Y=\beta 0+\beta 1 X)$ quadratic fitness $\left(Y=\beta 0+\beta 1 X+\beta 2 X^{2}\right)$, cubic fitness $(Y=\beta 0$ $\left.+\beta 1 X+\beta 2 X^{2}+\beta 3 X^{3}\right)$ and exponential fitness $(Y=$ $\left.\mathrm{e}^{\beta 0+\beta 1 X}\right)$. The statistical analysis was performed with the IBM SPSS Statistics software package, version 19.0 (IBM Corporation, Armonk, NY, USA). Values of $\mathrm{p}<0.05$ were considered statistically significant. In the models, $\beta_{0}$ was the mean annual rate, $\beta_{1}$ was the coefficient of linear effect (speed), and $\beta_{2}$ was the coefficient of quadratic effect (acceleration).

\section{RESULTS}

\section{Descriptive analysis}

In the general population of Brazil, the absolute number of asthma-related deaths dropped from 2,286 in 1980 to 2,096 in 2014 . The crude asthma mortality rate dropped from 1.92 to 1.03 deaths per 100,000 population, corresponding to a $46.2 \%$ reduction, between 1980 and 2014 (Tables 1 and 2).

Death certificate data showed that the number of asthma-related deaths among individuals $\leq 34$ years of age decreased by $67 \%$ over the period studied, dropping from 803 (35.1\% of all asthma-related deaths) in 1980 to 262 (12.5\% of all asthma-related deaths) in 2014 (Table 1). Asthma-related deaths in the 0 - to 4 -year age group accounted for $26.1 \%$ of all such deaths in 1980, a figure that decreased to $3.8 \%$ in 2014. In that same age group, the age-adjusted asthma mortality rate decreased by $85.2 \%$ over the study period, from $3.63 / 100,000$ population in 1980 to $0.54 / 100,000$ population in 2014 (Table 2). There was less variation in the absolute number of deaths and its representativeness in the 5- to 34-year age group than in the 0 - to 4-year age group. In the former group, the number of asthma-related deaths decreased from 207 (9.1\% of all such deaths) in 1980 to 182 ( $8.7 \%$ of all such deaths) in 2014 . It is of note that the age-adjusted asthma mortality rate for the 5 - to 34 -year age group decreased by $81.3 \%$ over the study period-from $0.95 / 100,000$ population in 1980 to $0.18 / 100,000$ population in 2014 (Tables 1 and 2).

\section{Trend analysis}

The curve estimation model best representing the age-adjusted trends in asthma mortality for the 0 - to 4-year and 5- to 34-year age groups showed a linear and constant trend toward a decrease during the period analyzed. The general mortality trend in Brazil (crude asthma mortality rate) showed a polynomial fit during the period analyzed, an initial decrease being followed by an increase that was then followed by another decrease (Figure 1).

In the 0 - to 4-year age group, there was a constant downward trend, with a mean annual decrease $\left(\beta_{1}\right)$ of 0.091 deaths $/ 100,000$ population and an adjusted $R^{2}$ of 0.953 . In the 5 - to 34-year age group, there was a mean annual decrease of 0.019 deaths $/ 100,000$ population and an adjusted $\mathrm{R}^{2}$ of 0.866 . Despite differences concerning the speed of the decline, similar trends were observed in the two age groups evaluated (Table 3).

After 2004, governmental asthma control policies increased the availability of inhaled corticosteroids in Brazil, thus reversing the annual trend in overall asthma mortality rates, which shifted from an increase of 0.018 deaths $/ 100,000$ population before 2004 to a decrease of 0.05 deaths/100,000 population after 2004 . A similar shift was observed in the 5- to 34-year age group, in which there was a linear, downward polynomial fit, the annual asthma mortality rates decreasing by 
Table 1. Asthma-related deaths, by age group, in Brazil-1980-2014.

\begin{tabular}{|c|c|c|c|c|}
\hline Year of death & $\begin{array}{l}0-4 \text { years } \\
\text { (\% total) }\end{array}$ & $\begin{array}{c}\text { 5-34 years } \\
\text { (\% total) }\end{array}$ & $\begin{array}{c}\text { 0-34 years } \\
\text { (\% total) }\end{array}$ & $\begin{array}{c}\text { Total asthma- } \\
\text { related deaths in } \\
\text { Brazil }\end{array}$ \\
\hline 1980 & $596(26.07)$ & $207(9.06)$ & $803(35.13)$ & 2286 \\
\hline 1981 & $529(25.84)$ & $194(9.48)$ & $723(35.32)$ & 2047 \\
\hline 1982 & $591(27.72)$ & $200(9.38)$ & 791 (37.10) & 2132 \\
\hline 1983 & $556(25.35)$ & $202(9.21)$ & $758(34.56)$ & 2193 \\
\hline 1984 & $502(25.23)$ & $215(10.80)$ & 717 (36.03) & 1990 \\
\hline 1985 & $466(24.60)$ & 193 (10.19) & 659 (34.79) & 1894 \\
\hline 1986 & $406(20.38)$ & $186(9.34)$ & $592(29.72)$ & 1992 \\
\hline 1987 & $380(21.75)$ & $196(11.22)$ & $576(32.97)$ & 1747 \\
\hline 1988 & $402(21.28)$ & $174(9.21)$ & $576(30.49)$ & 1889 \\
\hline 1989 & 364 (19.69) & $226(12.22)$ & $590(31.91)$ & 1849 \\
\hline 1990 & 391 (19.54) & $193(9.65)$ & $584(29.19)$ & 2001 \\
\hline 1991 & 305 (17.99) & $153(9.03)$ & $458(27.02)$ & 1695 \\
\hline 1992 & 354 (17.49) & $207(10.23)$ & $561(27.72)$ & 2024 \\
\hline 1993 & 309 (13.89) & $211(9.48)$ & $520(23.37)$ & 2225 \\
\hline 1994 & $331(14.45)$ & $246(10.74)$ & 577 (25.19) & 2291 \\
\hline 1995 & 330 (13.49) & $251(10.26)$ & $581(23.74)$ & 2447 \\
\hline 1996 & 255 (10.17) & $278(11.08)$ & $533(21.25)$ & 2508 \\
\hline 1997 & $288(10.78)$ & $278(10.41)$ & $566(21.19)$ & 2671 \\
\hline 1998 & $259(9.51)$ & $254(9.33)$ & $504(18.51)$ & 2723 \\
\hline 1999 & $236(8.66)$ & $289(10.61)$ & $525(19.27)$ & 2725 \\
\hline 2000 & $239(9.20)$ & $224(8.62)$ & $463(17.82)$ & 2598 \\
\hline 2001 & $226(8.87)$ & $225(8.83)$ & $451(17.70)$ & 2548 \\
\hline 2002 & $220(9.14)$ & $220(9.14)$ & $440(18.27)$ & 2408 \\
\hline 2003 & 225 (9.05) & $212(8.53)$ & 437 (17.59) & 2485 \\
\hline 2004 & 160 (6.25) & $212(8.29)$ & $372(14.54)$ & 2558 \\
\hline 2005 & $193(7.41)$ & $250(9.60)$ & $443(17.02)$ & 2603 \\
\hline 2006 & $191(6.14)$ & $263(8.45)$ & 454 (14.59) & 3111 \\
\hline 2007 & 165 (5.77) & $231(8.07)$ & $396(13.84)$ & 2862 \\
\hline 2008 & 121 (4.49) & $223(8.27)$ & $344(12.76)$ & 2696 \\
\hline 2009 & $123(4.83)$ & $203(7.98)$ & $326(12.81)$ & 2544 \\
\hline 2010 & $106(4.03)$ & 234 (8.89) & $340(12.92)$ & 2632 \\
\hline 2011 & 77 (3.15) & $178(7.28)$ & $256(10.47)$ & 2445 \\
\hline 2012 & $97(4.12)$ & $201(8.53)$ & $298(12.66)$ & 2354 \\
\hline 2013 & $79(3.31)$ & $216(9.05)$ & $295(12.35)$ & 2387 \\
\hline 2014 & $80(3.82)$ & $182(8.68)$ & $262(12.5)$ & 2096 \\
\hline
\end{tabular}

0.018 deaths $/ 100,000$ population before 2004 and by 0.046 deaths $/ 100,000$ population thereafter. After the introduction of treatment with inhaled corticosteroids (in 2004), there was an uptick in the observed downward trend for asthma mortality rates in the 0 - to 4-year age group, the mean annual decline $\left(\beta_{1}\right)$ being 0.092 deaths $/ 100,000$ population before 2004 and 0.074 deaths $/ 100,000$ population thereafter. It is of note that, when the post-2004 trends in all age groups were analyzed separately, age-adjusted and crude asthma mortality coefficients both showed un upward shift after 2012 or 2013 (Table 3).

\section{DISCUSSION}

This article demonstrates that, in Brazil, there was a linear decline in age-adjusted asthma mortality coefficients from 1980 to 2014 in the 0- to 4-year and 5- to 34-year age groups in Brazil, in contrast with the third-order polynomial fits (decreasing, increasing, and again decreasing) for the crude asthma mortality rates during the period studied. The reduction in asthma mortality coefficients was more prominent in the 0 - to 4-year age group than in the 5- to 34-year age group, as was the decrease in the proportional representation in relation to the overall number of asthma-related deaths during the period analyzed. In the former group, we observed no significant change in mortality trends after 2004 (when treatment with inhaled corticosteroids became more widely available), whereas there was a marked decrease in asthma mortality rates after 2004 in the 5- to 34-year age group, as well as in older age groups.

Some potential limitations to the accuracy of population-based studies on asthma mortality should be considered. First of all, when the possibility that asthma 
Table 2. Age-adjusted and crude asthma mortality rates, by age group, in Brazil-1980-2014.

\begin{tabular}{|c|c|c|c|}
\hline Year & $\begin{array}{c}0 \text { to } 4 \text { years } \\
\text { (age-adjusted) }\end{array}$ & $\begin{array}{l}5 \text { to } 34 \text { years } \\
\text { (age-adjusted) }\end{array}$ & $\begin{array}{l}\text { All age groups } \\
\text { (crude) }\end{array}$ \\
\hline 1980 & 3.6279 & 0.9536 & 1.9207 \\
\hline 1981 & 3.2371 & 0.9042 & 1.6895 \\
\hline 1982 & 3.6125 & 0.9027 & 1.7224 \\
\hline 1983 & 3.3948 & 0.8709 & 1.7349 \\
\hline 1984 & 3.0616 & 0.915 & 1.5423 \\
\hline 1985 & 2.8389 & 0.797 & 1.4387 \\
\hline 1986 & 2.4708 & 0.7487 & 1.484 \\
\hline 1987 & 2.3101 & 0.7826 & 1.2772 \\
\hline 1988 & 2.4413 & 0.6684 & 1.3562 \\
\hline 1989 & 2.2083 & 0.8629 & 1.3047 \\
\hline 1990 & 2.3697 & 0.7231 & 1.3887 \\
\hline 1991 & 1.8461 & 0.5544 & 1.1544 \\
\hline 1992 & 2.1958 & 0.7387 & 1.3612 \\
\hline 1993 & 1.8182 & 0.7576 & 1.468 \\
\hline 1994 & 1.9196 & 0.8352 & 1.4903 \\
\hline 1995 & 1.8876 & 0.873 & 1.5723 \\
\hline 1996 & 1.6321 & 0.6402 & 1.5967 \\
\hline 1997 & 1.8122 & 0.6101 & 1.6731 \\
\hline 1998 & 1.6075 & 0.5256 & 1.683 \\
\hline 1999 & 1.4441 & 0.6326 & 1.6621 \\
\hline 2000 & 1.4594 & 0.4692 & 1.53 \\
\hline 2001 & 1.3583 & 0.4736 & 1.478 \\
\hline 2002 & 1.3044 & 0.4357 & 1.3788 \\
\hline 2003 & 1.3164 & 0.4159 & 1.4049 \\
\hline 2004 & 0.9238 & 0.4075 & 1.4281 \\
\hline 2005 & 1.0823 & 0.4842 & 1.4132 \\
\hline 2006 & 1.0556 & 0.4614 & 1.6656 \\
\hline 2007 & 0.9974 & 0.4673 & 1.5116 \\
\hline 2008 & 0.7542 & 0.4661 & 1.4218 \\
\hline 2009 & 0.784 & 0.4149 & 1.3285 \\
\hline 2010 & 0.7683 & 0.2358 & 1.3797 \\
\hline 2011 & 0.4939 & 0.1736 & 1.2709 \\
\hline 2012 & 0.6313 & 0.1961 & 1.2135 \\
\hline 2013 & 0.5216 & 0.2110 & 1.1852 \\
\hline 2014 & 0.5355 & 0.1783 & 1.0335 \\
\hline Delta (1980 vs. 2014 ) & $-85.2 \%$ & $-81.3 \%$ & $-46.2 \%$ \\
\hline
\end{tabular}

was a secondary diagnosis has been excluded, especially in cases in which nonspecific respiratory failure was listed as the underlying cause of death, cases in which death could have been attributed to asthma exacerbation can be lost. Goldacre et al.(14) suggested that, in population-based studies, half of all asthma-related deaths are missed when only the underlying cause of death is considered. Underreporting constitutes another possible information bias, especially if mortality statistics depend on a deficient hospital-based health care system. In addition, there are possible diagnostic limitations and imprecise data employed when the death certificate is filled out. Furthermore, the change from ICD-9 codes to ICD-10 codes (in 1996) could have resulted in misinterpretations.

In the 0 - to 4-year and 5- to 34-year age groups, there was a constant decline in asthma mortality rates over the 30-year period analyzed, whereas the crude asthma mortality rates showed a nonlinear trend.
The younger group showed an $85.2 \%$ decrease in the age-adjusted asthma mortality rate, with a steady drop in its representativeness-from $26.07 \%$ to $3.82 \%$ of the overall absolute number of asthma-related deaths-during the period studied. The annual decrease of 0.0917 deaths $/ 100,000$ population in that age group (comprising 11.2 million individuals in Brazil) resulted in a significant decrease of more than 12 asthma-related deaths per year.

Despite the importance of the 0- to 4-year age group, there are certain challenges intrinsic to the diagnosis of asthma in very young children. Those challenges include making the differential diagnosis with diseases that have a similar clinical presentation (breathlessness and wheezing), such as bronchiolitis obliterans, foreign body aspiration, chest tumors, and malformations, as well as the difficulties in performing diagnostic procedures, such as spirometry tests with bronchodilators, in very young children. ${ }^{(15)}$ 


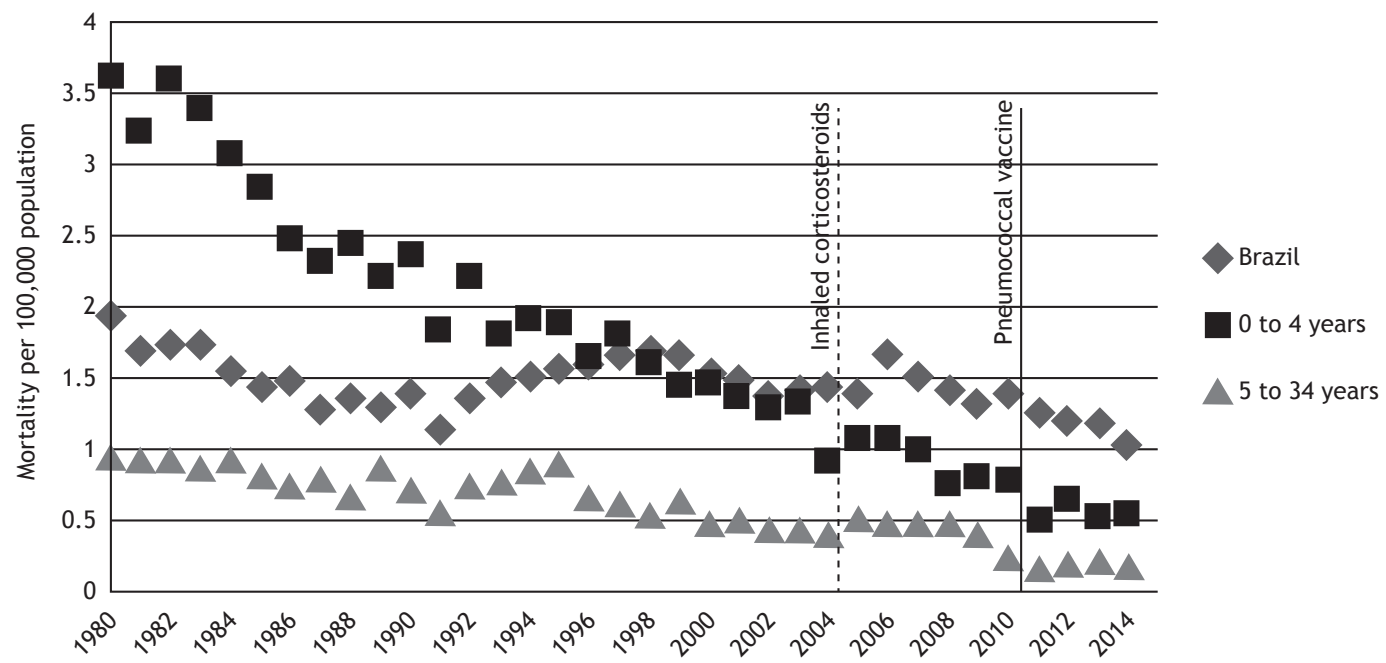

Figure 1. Crude and age-adjusted asthma mortality rates and trends in individuals in the 0- to 4-year and 5- to 34-year age groups in Brazil, from 1980 to 2014.

Although there was an $81.3 \%$ decrease in asthma mortality rates in the 5- to 34-year age group, there were no significant differences concerning the proportional contribution of that age group to the total number of asthma-related deaths in Brazil, which ranged from $9.06 \%$ to $8.68 \%$ of the absolute number of asthma-related deaths from 1980 to 2014 . The annual decrease of 0.026 deaths $/ 100,000$ population in that age group (comprising 100.1 million individuals in Brazil) resulted in a mean decrease of 26 asthma-related deaths per year. It is noteworthy that, in the 5- to 34-year age group, the annual asthma mortality rate decreased by 0.018 deaths $/ 100,000$ population in 1980 and by 0.046 deaths $/ 100,000$ population in 2004 . That was a linear decline that more than doubled the number of lives spared. Although that decline was less pronounced than the decline observed in the 0 - to 4-year age group, it was equally significant in terms of the absolute numbers. Data obtained for the 5- to 34-year age group are of particular interest because of the better chances of obtaining a correct asthma diagnosis and preventing triggering events in individuals within that population, as well as because that age group accounted for most of the increase in asthma mortality rates seen during the $1980 s^{(16)}$

Recent studies have demonstrated stable or decreasing asthma mortality rates in most developed countries. ${ }^{(17)}$ Prietsch et al. ${ }^{(18)}$ recently reported a decrease in asthma mortality among pediatric patients ( $\leq 19$ years of age) in Brazil as a whole, as was subsequently reported for the city of Rio de Janeiro. ${ }^{(19)}$ Another recent study reported that asthma mortality rates have decreased in Brazil since the 1990s. ${ }^{(20)}$

We find it interesting that the linear downward trend observed in the present study did not apply to the crude asthma mortality rates. Rather, the crude asthma mortality rates showed a trend with three distinct phases: an initial downward trend from 1980 to 1989; an upward trend from 1990 to 2000; and another downward trend from 2001 to 2014. This behavior contrasts with the findings of a meta-analysis of asthma mortality trends in 20 countries, which, despite some variability across studies, showed a mean increase of $38 \%$ in asthma mortality rates from the mid-1970s to the mid-1980s, followed by a mean decrease of $63 \%$ from the end of the 1980 s to the year 2005. ${ }^{(11)}$ Although more data are needed, the crude asthma mortality rates apparently showed a major shift in trend in those countries, from an annual increase of 0.022 deaths $/ 100,000$ population from 1980 to 2004 to an annual decrease of 0.05 deaths $/ 100,000$ population thereafter. More recent asthma mortality studies have shown a decrease in mortality rates in various countries, including Serbia, Puerto Rico, Scotland, and the United States. ${ }^{(21-24)}$ Therefore, we could expect a similar reduction in crude asthma mortality rates to occur in Brazil after 2004, the year that inhaled corticosteroids became available in public health care systems.

Although a correlation between the reduction in asthma mortality and the widespread use of inhaled corticosteroids to control airway inflammation has been proposed by some authors, ${ }^{(25-27)}$ no specific studies have been conducted in order to investigate that correlation. In Brazil, the Unified Health Care System has been providing inhaled corticosteroids for patients with persistent asthma since 2004, when the Primary Health Care Guidelines for Asthma and Rhinitis were published, with the objective of broadening the scope of the health care provided to such patients. ${ }^{(28)}$ That promoted the new downward trend in asthma mortality among individuals over 5 years of age. In addition to asthma control drugs, the inclusion of the pneumococcal vaccine in the Brazilian Immunization Program might also have played an important role in inducing the downward trend in asthma mortality, although it only recently came to be recommended for use in children under 2 years of age and there are therefore as yet no consistent data to be analyzed. 
Table 3. Trend analysis of crude and age-adjusted asthma mortality rates, by age group, in Brazil-1980-2014.

\begin{tabular}{|c|c|c|c|c|c|c|c|}
\hline $\begin{array}{c}\text { Asthma } \\
\text { mortality }\end{array}$ & $\begin{array}{c}\text { Mean beta } \\
\text { coefficient } \\
\left(\beta_{0}\right)\end{array}$ & $\begin{array}{c}\text { Mean } \\
\text { annual } \\
\text { increase } \\
\left(\beta_{1}\right)\end{array}$ & $\left(\beta_{2}\right)$ & Acceleration & $\begin{array}{c}\text { p-value } \\
\text { (F) }\end{array}$ & $\begin{array}{c}\text { Adjusted } \\
\mathbf{R}^{2}\end{array}$ & Trend \\
\hline All age groups & 1.483 & 0.018028 & -0.000262 & -0.000151 & $<0.001$ & 0.639 & $\begin{array}{l}\text { Third-order } \\
\text { polynomial fit } \\
\text { Decreasing from } \\
1980 \text { to } 1989 ; \\
\text { increasing from } \\
1990 \text { to } 2001 \text {; and } \\
\text { decreasing from } \\
2002 \text { to } 2014\end{array}$ \\
\hline 0- to 4-year & 1.717034 & -0.091762 & & & $<0.001$ & 0.953 & Linear decline \\
\hline 5- to 34-year & 0.593431 & -0.021520 & & & $<0.001$ & 0.866 & Linear decline \\
\hline $\begin{array}{l}\text { All age groups } \\
\text { before } 2004^{b}\end{array}$ & 1.497 & 0.022395 & -0.001001 & 0.000228 & $<0.001$ & 0.624 & $\begin{array}{l}\text { Third-order } \\
\text { polynomial fit } \\
\text { Decreasing from } \\
1980 \text { to } 1987 ; \\
\text { increasing from } \\
1988 \text { to } 1998 ; \text { and } \\
\text { decreasing from } \\
1999 \text { to } 2004\end{array}$ \\
\hline $\begin{array}{l}0 \text { - to } 4 \text {-year } \\
\text { before } 2004\end{array}$ & 1.935 & -0.092283 & & & $<0.001$ & 0.951 & Linear decline \\
\hline $\begin{array}{l}5 \text { - to } 34 \text {-year } \\
\text { before } 2004\end{array}$ & 0.654108 & -0.018479 & & & $<0.001$ & 0.728 & Linear decline \\
\hline $\begin{array}{l}\text { All age groups } \\
\text { after } 2004\end{array}$ & 1.328294 & -0.050429 & 0.005388 & & 0.021 & 0.526 & $\begin{array}{l}\text { Second-order } \\
\text { polynomial fit } \\
\text { Decreasing from } \\
2005 \text { to } 2013 \\
\text { and increasing } \\
\text { thereafter }\end{array}$ \\
\hline $\begin{array}{l}0 \text { - to } 4 \text {-year } \\
\text { after } 2004\end{array}$ & 0.724580 & -0.074360 & 0.009151 & & $<0.001$ & 0.850 & $\begin{array}{l}\text { Second-order } \\
\text { polynomial fit } \\
\text { Decreasing from } \\
2005 \text { to } 2012 \\
\text { and increasing } \\
\text { thereafter }\end{array}$ \\
\hline $\begin{array}{l}5 \text { - to } 34 \text {-year } \\
\text { after } 2004\end{array}$ & 0.310778 & -0.043610 & 0.005037 & & 0.003 & 0.711 & $\begin{array}{l}\text { Second-order } \\
\text { polynomial fit } \\
\text { Decreasing from } \\
2005 \text { to } 2012 \\
\text { and increasing } \\
\text { thereafter }\end{array}$ \\
\hline
\end{tabular}

avalues expressed as deaths/100,000 population. ${ }^{b}$ When treatment with inhaled corticosteroids became widely available.

Other factors might contribute to the decrease in asthma mortality, such factors including health and well-being improvements achieved through policies of inclusion in public health programs, such as the Family Health Program, resulting in a successful reduction in the number of ambulatory care-sensitive hospitalizations for a group of diseases, including asthma, for which access to effective primary care can reduce the likelihood of hospitalization, (29) as well as asthma-specific programs, which promote the identification of patients with severe asthma and efficient asthma control, with the expected reduction in the rates of mortality either directly or indirectly associated with asthma. ${ }^{(30)}$ Recent studies have demonstrated that, in regions of Brazil where there is considerable social inequality, asthma mortality is correlated with poor access to health systems and asthma programs. ${ }^{(31)}$ Unfortunately, data on reliable social indicators, which could further understanding of the effects that such indicators have on asthma in Brazil, are scarce and conflicting.

Within the population studied here, asthma mortality trends should follow the prevalence of severe asthma. In a study comparing phases one and three of the International Study of Asthma and Allergies in Childhood, ${ }^{(32)}$ the prevalence of severe asthma symptoms in the pediatric population was found to be stable after a 7-year follow-up period. Given that the prevalence of severe asthma remained unchanged, that finding 
suggests that other factors are involved. In addition to the incorporation of inhaled corticosteroids into public policies to control asthma in Brazil, factors that might play roles include increased diagnostic accuracy, expanded vaccination programs, and improvements in the reporting of deaths. The contribution of each of those factors is difficult to assess and, despite obvious advances, asthma control in Brazil continues to be insufficient.

Further studies, evaluating the correlation between asthma mortality and health inclusion programs, as well as between asthma mortality and specific socioeconomic indicators, could help explain the causes of the differences observed in the trends. Case-control studies of asthma deaths and near-deaths can provide additional insights into the risk factors associated with severe asthma attacks. In conclusion, we have shown that there has been a consistent decrease in asthma mortality among individuals 0-34 years of age in Brazil, and that that decrease has been more pronounced in the subset of individuals 5-34 years of age since the introduction of public policies that made treatment with inhaled corticosteroids more widely available. However, further studies are needed in order to identify the causes of this decrease, within this age group, as well as within age groups in which asthma mortality rates are higher, given that the crude asthma mortality rates continue to oscillate.

\section{ACKNOWLEDGMENTS}

We are grateful to Ivan Duarte and Marcelo Santos, for their help in collecting data.

\section{REFERENCES}

1. National Asthma Education and Prevention Program. Expert Pane Report 3 (EPR-3): Guidelines for the Diagnosis and Management of Asthma-Summary Report 2007. J Allergy Clin Immunol. 2007;120(5 Suppl):S94-138. Erratum in: J Allergy Clin Immunol. 2008;121(6):1330. https://doi.org/10.1016/j.jaci.2007.09.029

2. Sociedade Brasileira de Pneumologia e Tisiologia. Diretrizes da Sociedade Brasileira de Pneumologia e Tisiologia para o Manejo da Asma 2012. J Bras Pneumol. 2012;38(Suppl 1):S1-S46

3. Salto Júnior JJ, Wandalsen G, Naspitz CK, Solé D. Asthma and respiratory disease mortality rates in the state of Sao Paulo, Brazil: 1970-1996. Allergol Immunopathol (Madr). 2002;30(1):30-5. https:// doi.org/10.1016/S0301-0546(02)79084-8

4. Guarnieri $M$, Balmes, JR. Outdoor air pollution and asthma Lancet. 2014;383(9928):1581-92. https://doi.org/10.1016/S0140 6736(14)60617-6

5. Friedlander JL, Sheehan WJ, Baxi SN, Kopel LS, Gaffin JM, Ozonoff A, et al. Food allergy and increased asthma morbidity in a Schoobased Inner-City Asthma Study. J Allergy Clin Immunol Pract 2013;1(5):479-84. https://doi.org/10.1016/j.jaip.2013.06.007

6. Chatkin JM, Barreto SM, Fonseca NA, Gutiérrez CA, Sears MR. Trends in asthma mortality in young people in southern Brazil. Ann Allergy Asthma Immunol. 1999;82(3):287-92. https://doi.org/10.1016/ S1081-1206(10)62610-5

7. Neffen H, Fritscher $C$, Schacht FC, Levy G, Chiarella P, Soriano $\mathrm{JB}$, et al. Asthma control in Latin America: the Asthma Insights and Reality in Latin America (AIRLA) survey. Rev Panam Salud Publica. 2005;17(3):191-7. https://doi.org/10.1590/S1020 49892005000300007

8. D'Amato G. Effects of climatic changes and urban air pollution on the rising trends of respiratory allergy and asthma. Multidiscip Respir Med. 2011;6(1):28-37. https://doi.org/10.1186/2049-6958-6-1-28

9. Sheffield PE, Knowlton K, Carr JL, Kinney PL. Modeling of regional climate change effects on ground-level ozone and childhood asthma. Am J Prev Med. 2011;41(3):251-7; quiz A3.

10. Antó JM. Recent advances in the epidemiologic investigation of risk factors for asthma: a review of the 2011 literature. Curr Allergy Asthma Rep. 2012;12(3):192-200. https://doi.org/10.1007/s11882 012-0254-7

11. Wijesinghe $M$, Weatherall $M$, Perrin $K$, Crane $J$, Beasley $R$ International trends in asthma mortality rates in the 5- to 34-year age group: a call for closer surveillance. Chest. 2009:135(4):1045-9. https://doi.org/10.1378/chest.08-2082

12. Ahmad S, Agrawal S, Pal A, Lee H. Prevalence of allergies, asthma severity, and asthma control in inner-city asthmatic children in 0-4 years of age [abstract]. Am J Respir Crit Care Med. 2015;191,A4178.

13. Akinbami LJ, Moorman JE, Bailey C, Zahran HS, King M, Johnson $\mathrm{CA}$, et al. Trends in asthma prevalence, health care use, and mortality in the United States, 2001-2010. NCHS Data Brief. 2012;(94):1-8.

14. Goldacre MJ, Duncan ME, Griffith M. Death rates for asthma in English populations 1979-2007: comparison of underlying cause and all certified causes. Public Health. 2012;126(5):386-93. https://doi. org/10.1016/..puhe.2012.01.022

15. Bacharier LB, Guilbert TW. Diagnosis and management of early asthma in preschool-aged children. J Allergy Clin Immunol. 2012;130(2):287-96; quiz 297-8. https://doi.org/10.1016/j. jaci.2012.04.025

16. Sears MR. Worldwide trends in asthma mortality. Bull Int Union Tuberc Lung Dis. 1991;66(2-3):79-83.

17. Martinez FD. Trends in asthma prevalence, admission rates, and asthma deaths. Respir Care. 2008;53(5):561-5; discussion 565-7.

18. Prietsch SO, Zhang L, Catharino AR, Vauchinski L, Rodrigues FE. Asthma mortality among Brazilian children up to 19 years old between 1980 and 2007. J Pediatr (Rio J). 2012;88(5):384-8. https:// doi.org/10.2223/jped.2215

19. Silva EM, Silva GA. Asthma-related mortality in the city of Rio de Janeiro, Brazil, 2000-2009: a multicausal analysis [Article in Portuguese]. Cad Saude Publica. 2013;29(4):667-80. https://doi. org/10.1590/S0102-311X2013000800005

20. Lotufo PA, Bensenor IM. Temporal trends of asthma mortality rates in Brazil from 1980 to 2010. J Asthma. 2012;49(8):779-84. https://doi. org/10.3109/02770903.2012.693237

21. Pesut DP, Bulajic MV, Nagomi-Obradovic LM, Grgurevic AD Gledovic ZB, Ponomarev DR, et al. Asthma mortality in Serbia: a 30-year analysis. Respir Med. 2011;105 Suppl 1:S50-3. https://doi. org/10.1016/S0954-6111(11)70011-7

22. Bartolomei-Díaz JA, Amill-Rosario A, Claudio L, Hernández W. Asthma mortality in Puerto Rico: 1980-2007. J Asthma. 2011;48(2):202-9. https://doi.org/10.3109/02770903.2010.528498

23. Roberts NJ, Lewsey JD, Gillies M, Briggs $A H$, Belozerov V, Globe DR, Chiou CF, Lin SL, Globe G. Time trends in 30 day casefatality following hospitalisation for asthma in adults in Scotland: a retrospective cohort study from 1981 to 2009. Respir Med. 2013;107(8):1172-7. https://doi.org/10.1016/j.rmed.2013.04.004

24. Moorman JE, Akinbami LJ, Bailey CM, Zahran HS, King ME, Johnson CA, et al. National surveillance of asthma: United States, 2001-2010. Vital Health Stat 3. 2012;(35):1-58.

25. Sly RM. Association of decreases in asthma mortality with increases in sales of inhaled corticosteroids. J Allergy Clin Immunol. 2000;106(4):782. https://doi.org/10.1067/mai.2000.110470

26. Tual S, Godard P, Piau JP, Bousquet J, Annesi-Maesano I. Asthmarelated mortality in France, 1980-2005: decline since the last decade. Allergy. 2008;63(5):621-3. https://doi.org/10.1111/j.13989995.2008.01657.x

27. Kumana CR, Kou M, Lauder IJ, Ip MS, Lam WK. Increasing use of inhaled steroids associated with declining asthma mortality. $J$ Asthma. 2001;38(2):161-7. https://doi.org/10.1081/JAS-100000035

28. Amaral LM, Palma PV, Leite IC. Evolution of public policies and programs for asthma control in Brazil from the perspective of consensus guidelines. J Bras Pneumol. 2012;38(4): 518-25. https:// doi.org/10.1590/S1806-37132012000400015

29. Alfradique ME, Bonolo Pde F, Dourado I, Lima-Costa MF, Macinko 
J, Mendonça CS, et al. Ambulatory care sensitive hospitalizations: elaboration of Brazilian list as a tool for measuring health system performance (Project ICSAP-Brazil) [Article in Portuguese]. Cad Saude Publica. 2009;25(6):1337-49. https://doi.org/10.1590/S0102311X2009000600016

30. Ponte E, Franco RA, Souza-Machado A, Souza-Machado C, Cruz, AA. Impact that a program to control severe asthma has on the use of Unified Health System resources in Brazil. $J$ Bras Pneumol. 2007;33(1):15-9. https://doi.org/10.1590/S180637132007000100006
31. Solé D, Camelo-Nunes IC, Wandalsen GF, Mallozi MC, Naspitz CK: Brazilian ISAAC'S Group. Is the prevalence of asthma and related symptoms among Brazilian children related to socioeconomic status? J Asthma. 2008;45(1):19-25. https://doi. org/10.1080/02770900701496056

32. Solé $D$, Melo KC, Camelo-Nunes IC, Freitas LS, Britto M, Rosário $N A$, et al. Changes in the prevalence of asthma and allergic diseases among Brazilian schoolchildren (13-14 years old): comparison between ISAAC Phases One and Three. J Trop Pediatr. 2007;53(1):13-21. https://doi.org/10.1093/tropej/fml044 